\title{
Dynamics of a Free-Living Nitrogen-Fixing Bacteria Population Lacking of Competitive Advantage Towards an Antagonistic Population
}

\author{
A. Kavadia ${ }^{\mathrm{a}, \mathrm{b}, \mathrm{c}}$, D.V. Vayenas ${ }^{\mathrm{b}}$, S. Pavlou ${ }^{\mathrm{c}}$ and G. Aggelis ${ }^{\mathrm{a}_{*}}$
}

\begin{abstract}
${ }^{a}$ Division of Genetics, Cell \& Development Biology, Department of Biology, University of Patras; ${ }^{b}$ Department of Environmental and Natural Resources Management, School of Natural Resources and Enterprise Management, Agrinion, University of Ioannina; ${ }^{c}$ Department of Chemical Engineering, University of Patras, and Institute of Chemical Engineering and High Temperature Chemical Processes-FORTH, Patras, Greece
\end{abstract}

\begin{abstract}
The dynamics of a model of a free-living nitrogen-fixing population, grown in a chemostat alone or in competition with a non-nitrogen-fixing population, was studied through bifurcation analysis. It is demonstrated that the ability of the nitrogen-fixing population to survive depends on the ammonia and carbon source concentrations and the kinetics parameters of the system. Under competitive conditions the nitrogen-fixing population, characterized by low growth rates, can survive alone at stable steady state only at low dilution rate values. Especially, there is a threshold of the dilution rate above which only the competitive population can survive.

When amensalistic interactions are established, coexistence of both populations is favored. At low dilution rate values the survival of the nitrogen-fixing population alone is restricted while this population can survive at higher ammonia concentrations either in coexistence state or in multistability state together with the competitive population. When nitrogen-fixing population successfully inhibits its competitor, then its survival is enhanced towards the coexistence state.
\end{abstract}

Keywords: Population dynamics, nitrogen fixation, competition, coexistence.

\section{INTRODUCTION}

The biogeochemical cycle of nitrogen is essential for agriculture, as well as for the productivity of natural ecosystems. Nitrogen being of major importance for all living organisms is often a limiting growth factor in soil ecosystem. Soil reservoirs are fed by biologically and/or by chemically fixed nitrogen (in the form of fertilizers), but the balance is frequently negative due to significant losses through denitrification, erosion, leaching and volatilization.

Biological nitrogen fixation is considered as the limiting step of the nitrogen cycle, as this process is functioned by a restricted number of prokaryotes, including bacteria of the genus Azospirillum and specific symbiotic associations [1-3]. Other organisms (animals, plants, microorganisms) require fixed forms of nitrogen.

Abiotic factors and biotic interactions affect the survival of free-living nitrogen-fixing populations. Within the chemical factors affecting nitrogen-fixing bacteria are included the concentration and nature of organic components excreted by plant roots [4-13], while within biotic interactions are included predation and parasitism, competition for resources and interspecific microbial interactions having either

*Address correspondence to this author at the Division of Genetics, Cell \& Development Biology, Department of Biology, University of Patras; Greece; Tel: +302610969260; Fax: +302610969260;

E-mail: George.Aggelis@upatras.gr negative (i.e. inhibitory) or positive (i.e., through the increase of nutrient availability) effects on the microbial community [14-19].

In the natural ecosystems the low concentration of the carbon source is critical for microbial growth and survival, especially for nitrogen-fixing populations, since the fixation of nitrogen is a highly energy consuming process [20]. Furthermore, the nitrogenase complex (responsible for the conversion of molecular nitrogen into ammonium), is inhibited by ammonium nitrogen, in both transcriptional and enzymatic activity levels [21]. Ammonium nitrogen under aerobic conditions enhances the growth of Azospirillum [22] but under high ammonium and low dissolved oxygen concentrations the growth is inhibited [10,23-25]. Under microaerobic conditions Azospirillum can grow in the presence of low ammonium nitrogen concentration, while after the depletion of ammonium nitrogen, they are able to grow by fixing molecular nitrogen [25-28].

Numerous mathematical models have been used in the study of interactions between species that share common resources and of the effect of predators on the dynamics of biological systems [29-39]. In the traditional models (i.e. in the Lotka-Volterra competition model and similar) the interaction of one species to the other is always negative, while coexistence occurs only if between-species competition is weaker than within species. Kooi and Kooiman [32] proved that a competitor can stabilize a nutrient-prey-predator system, while Zhang [40], introducing mutualism in competitive 
systems, showed that coexistence of populations is promoted while the carrying capacity of the system is enhanced.

Recently, the dynamics of free-living nitrogen-fixing populations in antagonistic and predation conditions was studied using several mathematical models [41, 42]. By means of bifurcation analysis it was shown that, under a variety of conditions, the presence of competitors and predators is beneficial for the system and enhances coexistence.

The aim of this work is to study the dynamics of a freeliving nitrogen-fixing population grown in a chemostat alone or together with a competitive non-nitrogen-fixing population. Specifically, it is reported the ability of the nitrogenfixing population to survive, although it is initially disadvantaged by a lower growth rate comparing to that of its competitor.

\section{MODELING}

Dynamics of nitrogen-fixing populations was studied using the following models published in Ecological Modeling [41], except for Model I which appears in this paper for the first time.

\section{Model I}

In the first model it is assumed that a nitrogen-fixing microbial population $\left(N_{1}\right)$ grows alone in a chemostat under both carbon and nitrogen limitation.

Equations of this system are:

Balance of $N_{1}$ populations:

$\frac{d N_{1}}{d t}=\left(r_{1}-D\right) \cdot N_{1}$

where, $r_{1}$ is the specific growth rates of the $N_{1}$ population and $D$ is the chemostat dilution rate.

Balance of carbon and energy source:

$$
\frac{d S}{d t}=D \cdot\left(S_{f}-S\right)-r_{1} \cdot N_{1} \cdot \frac{1}{Y_{N_{1} / S}}-r_{E} \cdot E \cdot N_{1} \cdot \frac{1}{Y_{N H_{3} / S}}
$$

where, $S_{f}$ and $S$ are the carbon source concentrations in the inlet and outlet medium, respectively; $Y_{N_{1} / s}$ is the yield coefficient of $N_{1}$ on $S ; E$ is the nitrogenase ${ }^{s}$ concentration (units per volume of $N_{1}$ ); $r_{E}$ is the specific rate of nitrogen fixation; $Y_{\mathrm{NH}_{3} / \mathrm{S}}$ is the ammonium nitrogen yield coefficient on $S$.

Balance of ammonium nitrogen:

$$
\frac{d N H_{3}}{d t}=D \cdot\left[\left(N H_{3}\right)_{f}-\left(N H_{3}\right)\right]+r_{E} \cdot E \cdot N_{1}-r_{1} \cdot N_{1} \cdot \frac{1}{Y_{N_{1} / N H_{3}}}
$$

where, $\left(\mathrm{NH}_{3}\right)_{f}$ and $\left(\mathrm{NH}_{3}\right)$ are the ammonium nitrogen concentrations in the inlet and outlet medium, respectively; $Y_{\mathrm{N}_{1} \mathrm{NH}_{3}}$ is the yield coefficient on ammonium nitrogen of $N_{1}$.

Balance of nitrogenase (units per volume of $N_{1}$ ):

$$
\frac{d E}{d t}=q_{E}-r_{D} \cdot E-r_{1} \cdot E
$$

where, $q_{E}$ is the specific rate of nitrogenase synthesis; $r_{D}$ is the specific rate of nitrogenase destruction. In Eq. (4) the term $r_{1}$.E represents the decrease of active protein concentration observed due to the increase of the cell volume [43].

The specific growth rate of the $N_{1}$ population is modeled by Monod's model [44] as modified by Graef and Andrews [45]:

$$
r_{1}\left(S, N H_{3}\right)=r_{1 \max } \cdot \frac{S}{K_{1 S}+S} \cdot \frac{N H_{3}}{K_{1 N H_{3}}+N H_{3}+\left(K_{i N H_{3}} \cdot\left(N H_{3}\right)^{2}\right)}(5)
$$

where, $r_{1 \max }$ is the maximum specific growth rate; $K_{1 S}$ and $K_{1 N H_{3}}$ are the saturation constants for $S$ and $\mathrm{NH}_{3}$, respectively; $K_{\mathrm{INH}_{3}}$ is the inhibition constant of ammonium nitrogen on $N_{1}$.

Nitrogen fixing activity is regulated in both nitrogenase synthesis (transcriptional regulation) and nitrogenase activity levels, as following (Eqs. 6-9).

The specific rate of nitrogenase synthesis is given as:

$q_{E}\left(Q, r_{1}\right)=a \cdot r_{1} \cdot Q$

where, $Q$ is described by

$Q\left(\mathrm{NH}_{3}\right)=\frac{1}{1+\mathrm{C} \cdot \mathrm{NH}_{3}}$

where $C$ is a parameter related to the nif operators found under catabolic repression. $Q$ is a function of the repressor compound $\left(\mathrm{NH}_{3}\right)$ [41] and accounts for modification of the rate of nitrogenase synthesis via a catabolic repression control mode.

The specific rate of nitrogen fixation is given by the equation,

$r_{E}\left(S, N H_{3}\right)=r_{E \max } \cdot \frac{K_{i E}}{K_{i E}+N H_{3}} \cdot \frac{S}{K_{S E}+S}$

where, $r_{E \max }$ is the maximum specific rate of nitrogen fixation; $K_{S E}$ is the saturation constant; $K_{i E}$ is the inhibition constant.

A conceptual diagram illustrating the system described by Model I is given in Fig. (1).

\section{Model II}

In the second model (described in Kavadia et al. [41]) it is assumed that a nitrogen-fixing microbial population $\left(N_{1}\right)$ grows in a chemostat, together with a competitive microbial population $\left(N_{2}\right)$, while no other interactions (except for competition for the common resources) between the two populations occur. The equations (1) and (4)-(8) concerning the nitrogen-fixing population are already presented in model I. Additional equations of this system are:

Balance of $N_{2}$ population:

$\frac{d N_{2}}{d t}=\left(r_{2}-D\right) \cdot N_{2}$ 


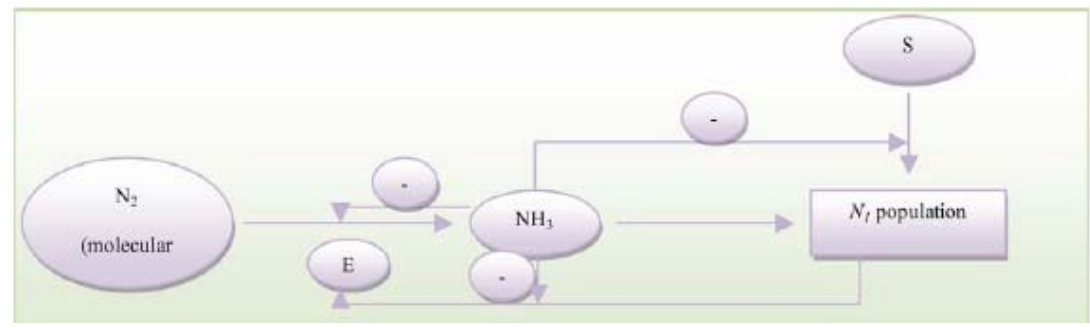

Fig. (1). Conceptual diagram which illustrates the model used for the study of the dynamics of a nitrogen-fixing population $\left(N_{l}\right)$ grown alone in a chemostat in the presence of ammonium nitrogen $\left(\mathrm{NH}_{3}\right)$. The limiting growth factors are the carbon and energy source $(\mathrm{S})$ and the $\mathrm{NH}_{3}$. When the concentration of $\mathrm{NH}_{3}$ is low in the growth environment, $\mathrm{S}$ is partitioned in order to sustain both, synthesis of cellular mass of $N_{l}$ and nitrogenase activity (E). When $\mathrm{NH}_{3}$ is accumulated in the growth environment, then, besides $N_{l}$ population, E synthesis and activity are inhibited.

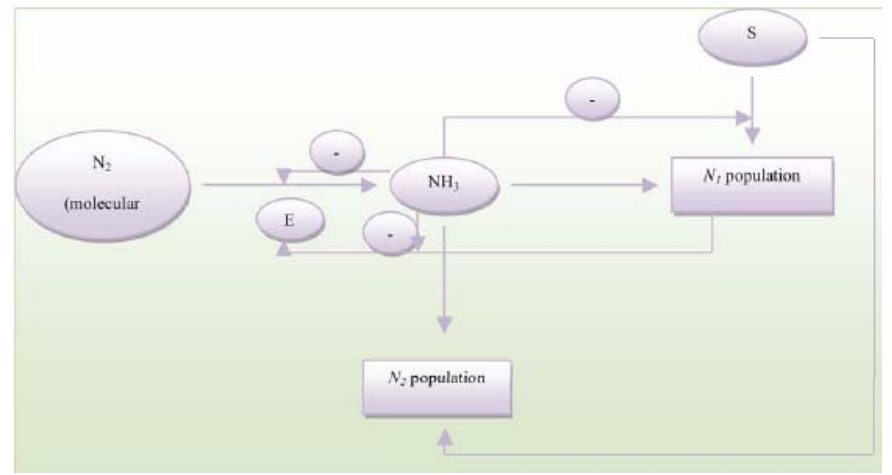

Fig. (2). Conceptual diagram which illustrates the models used for the study of the dynamics of a nitrogen-fixing population grown in antagonistic conditions. A nitrogen-fixing population $\left(N_{l}\right)$ grows together with a competitive microbial population $\left(N_{2}\right)$ in the presence of ammonium nitrogen $\left(\mathrm{NH}_{3}\right)$. The limiting growth factors are, for both populations, the carbon and energy source $(\mathrm{S})$ and the $\mathrm{NH}_{3}$. When the concentration of $\mathrm{NH}_{3}$ is low in the growth environment, $\mathrm{S}$ is partitioned in order to sustain both, synthesis of cellular mass of $N_{l}$ and nitrogenase activity (E). When $\mathrm{NH}_{3}$ is accumulated in the growth environment, then, besides $N_{l}$ population, E synthesis and activity are inhibited. The presence of $N_{2}$ population, however, could discharge the system from $\mathrm{NH}_{3}$, and therefore could promote survival of $N_{l}$ population.

where, $r_{2}$ is the specific growth rate of the $N_{2}$ population; $D$ is the chemostat dilution rate.

Balance of carbon and energy source:

$\frac{d S}{d t}=D \cdot\left(S_{f}-S\right)-r_{1} \cdot N_{1} \cdot \frac{1}{Y_{N_{1} / S}}-r_{2} \cdot N_{2} \cdot \frac{1}{Y_{N_{2} / S}}-r_{E} \cdot E \cdot \frac{1}{Y_{N H_{3} / S}} \cdot N_{1}{ }^{(10)}$ where, $S_{f}$ and $S$ are the carbon source concentrations in the inlet and outlet medium, respectively; $Y_{N_{1} / S}, Y_{N_{2} / S}$ are the yield coefficients of $N_{1}$ and $N_{2}$ on $S$, respectively; $E$ is the nitrogenase concentration (units per volume of $N_{1}$ ); $r_{E}$ is the specific rate of nitrogen fixation; $Y_{\mathrm{NH}_{3} / \mathrm{S}}$ is the ammonium nitrogen yield coefficient on $S$.

Balance of ammonium nitrogen:

$\frac{d N H_{3}}{d t}=D \cdot\left[\left(N H_{3}\right)_{f}-\left(N H_{3}\right)\right]+r_{E} \cdot E \cdot N_{1}-r_{1} \cdot N_{1} \cdot \frac{1}{Y_{N_{1}} / N H_{3}}-r_{2} \cdot N_{2} \cdot \frac{1}{Y_{N_{2} / N H_{3}}}$

where, $\left(\mathrm{NH}_{3}\right)_{f}$ and $\left(\mathrm{NH}_{3}\right)$ are the ammonium nitrogen concentrations in the inlet and outlet medium, respectively; $Y_{\mathrm{N}_{1} / \mathrm{NH}_{3}}$ and $Y_{\mathrm{N}_{2} / \mathrm{NH}_{3}}$ are the yield coefficients on ammonium nitrogen of $N_{1}$ and $N_{2}$, respectively.
The specific rate for microbial growth of the nonnitrogen-fixing population $\left(N_{2}\right)$ is given by the following equation:

$r_{2}\left(S, N H_{3}\right)=r_{2 \max } \cdot \frac{S}{K_{2 S}+S} \cdot \frac{N H_{3}}{K_{2 N H_{3}}+N H_{3}}$

where, $r_{2 \max }$ is the maximum specific growth rate of the $N_{2}$ population; $K_{2 S}$ and $K_{2 H_{3}}$ are the saturation constants for $\mathrm{S}$ and $\mathrm{NH}_{3}$, respectively.

A respective diagram illustrating the system described by Model II is given in Fig. (2).

\section{Model III}

The third model involves the ability of the nitrogenfixing population to establish an amensalistic interaction through the synthesis of an inhibitory substance released in the growth environment [41].

The balance equation for the inhibitor in the chemostat is used in addition to balance equations (1), (4) and (9)-(11) which describe model II:

$\frac{d I}{d t}=\left(a_{I} \cdot r_{1}+b_{I}\right) \cdot N_{1}-D \cdot I$ 


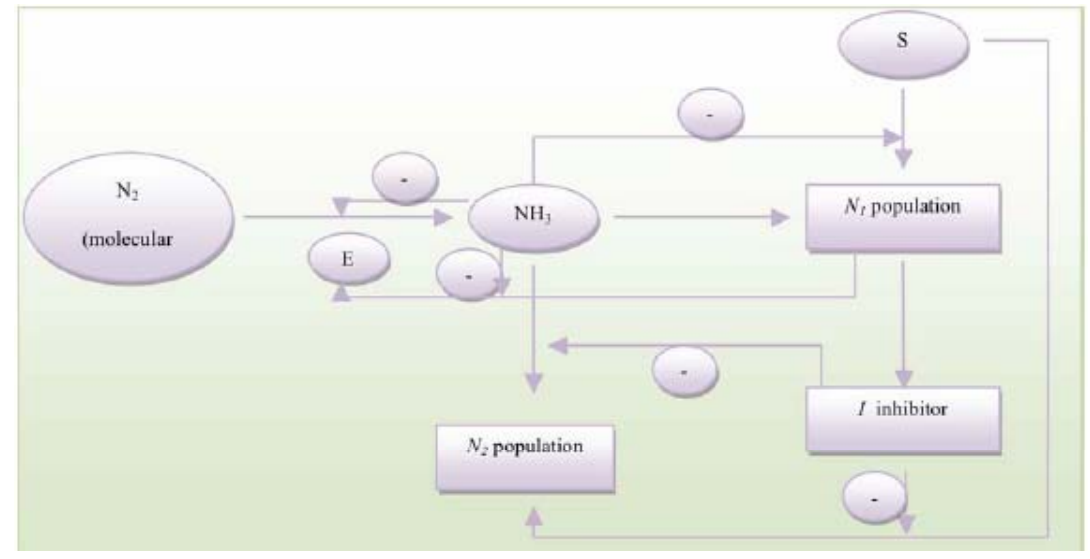

Fig. (3). Conceptual diagram which illustrates the model used for the study of the dynamics of a nitrogen-fixing population grown in amensalistic conditions. A nitrogen-fixing population $\left(N_{l}\right)$ grows together with a competitive microbial population $\left(N_{2}\right)$ in the presence of ammonium nitrogen $\left(\mathrm{NH}_{3}\right)$. The limiting growth factors are, for both populations, the carbon and energy source $(\mathrm{S})$ and the $\mathrm{NH}_{3}$. When the concentration of $\mathrm{NH}_{3}$ is low in the growth environment, $\mathrm{S}$ is partitioned in order to sustain both, synthesis of cellular mass of $N_{l}$ and nitrogenase activity (E). When $\mathrm{NH}_{3}$ is accumulated in the growth environment, then, besides $N_{l}$ population, E synthesis and activity are inhibited. The presence of $N_{2}$ population, however, could discharge the system from $\mathrm{NH}_{3}$, and therefore could promote survival of $N_{l}$ population. Additionally, the $N_{l}$ population is establishing an amensalistic interaction through the synthesis of an inhibitory substance (I) released in the growth environment.

where, $a_{I}$ is a stoichiometric constant for production of the inhibitor $(I)$ during primary metabolic growth; $b_{I}$ is a stoichiometric constant for production of the inhibitor $(I)$ during secondary metabolic growth.

Accordingly, equation (12) that describes specific growth rate of the $N_{2}$ population should be replaced by the following equation:

$r_{2}\left(S, N H_{3}\right)=r_{2 \max } \cdot \frac{S}{K_{2 S}+S} \cdot \frac{N H_{3}}{K_{2 N H_{3}}+N H_{3}} \cdot \frac{K_{i}}{K_{i}+I}$

where, $K_{i}$ is the inhibition constant.

The diagram illustrating this system is given in Fig. (3).

\section{METHODOLOGY}

The parameter values have major effect on the long-term behavior of the system. Of particular importance is the effect of the operating parameters, i.e. of the chemostat dilution rate $D$ controlled by the medium flowrate through the reactor and the ammonium nitrogen concentration in the feed.

The effect of the operating parameters on the system is illustrated through two-parameter bifurcation diagrams. The construction of these diagrams is accomplished by developing numerical algorithms based on the continuation algorithm AUTO [46]. For the three above-mentioned systems there are four possible steady states and the possibility of stable periodic states of coexistence of $N_{1}$ and $N_{2}$ in which the population densities in the chemostat vary periodically with time:

(1) Extinction of all populations: $N_{1}=N_{2}$ (washout state).

(2) Survival of $N_{1}$ only: $N_{1}>0, N_{2}=0\left(N_{1}\right.$ state).

(3) Survival of $N_{2}$ only: $N_{1}=0, N_{2}>0\left(N_{2}\right.$ state).
Other important parameters are the inhibition constant $K_{i N H 3}$ of ammonium nitrogen on the nitrogen-fixing population (representing the susceptibility of the nitrogen-fixing population to the ammonium containing media and affecting the specific growth rate of the $N_{1}$ population) and $r_{\max }$ and $K_{S}$ of the $N_{1}$ and $N_{2}$ populations that determine which population have the competitive advantage. The value of operating parameter $S_{f}$ for all bifurcation diagrams was kept constant at $S_{f}=5 \mathrm{~g} / \mathrm{L}$. The common parameter values used in all models for the cases studied in this paper were: $r_{1 \max }=0.15 \mathrm{~h}^{-1}, r_{2 \max }$ $=0.2 \mathrm{~h}^{-1}, r_{\text {Emax }}=0.2 \mathrm{~h}^{-1}, K_{i N H 3}=0.5 \mathrm{~g} / \mathrm{L}, K i=0.01$ or $0.2 \mathrm{~g} / \mathrm{L}$, $K_{I N H 3}=0.1 \mathrm{~g} / \mathrm{L}, K_{i E}=0.02 \mathrm{~g} / \mathrm{L}, K_{S E}=0.2 \mathrm{~g} / \mathrm{L}, Y_{N I / S}=0.3$, $Y_{N 1 / N H 3}=0.3, Y_{N H 3 / S}=0.1, C=50, a=2, r_{D E}=0.001 \mathrm{~h}^{-1}$, $K_{2 N H 3}=0.5 \mathrm{~g} / \mathrm{L}, Y_{N 2 / S}=0.3, Y_{N 2 / N H 3}=0.5, a_{i}=0.1, b_{i}=0.01$.

\section{RESULTS}

\subsection{Model I: Dynamics of a Nitrogen-Fixing Population Grown Alone in a Chemostat}

This system was studied for the case where the nitrogenfixing population grows alone in a chemostat. This simple model represents the base on which more complicated models of nitrogen-fixing dynamic systems can be developed.

Comparing this system to the conventional one (in which no nitrogen-fixing populations are involved), we observe that ammonium has a double effect on population growth and nitrogen fixation. In particular, ammonium in low concentrations has a positive effect on growth (as nitrogen constitutes a major nutrient), while in high concentrations inhibits both, the bacterial growth and nitrogenase synthesis. The ammonium concentrations in which the growth of the bacterial population and nitrogenase synthesis and activity are inhibited depends on the values of the parameters $K_{i N H 3}, \mathrm{C}$ and $K_{i E}$ (see equations 5, 7, 8). In Fig. (4) is shown a representative example of the above mentioned system, plotted as bifurcation diagram of $D$ vs $\left(\mathrm{NH}_{3}\right)_{f}$ for $S_{f}=5 \mathrm{~g} / \mathrm{L}$. This diagram consists of a transcritical bifurcation curve (marked $\mathrm{T}_{1}$ ), on 


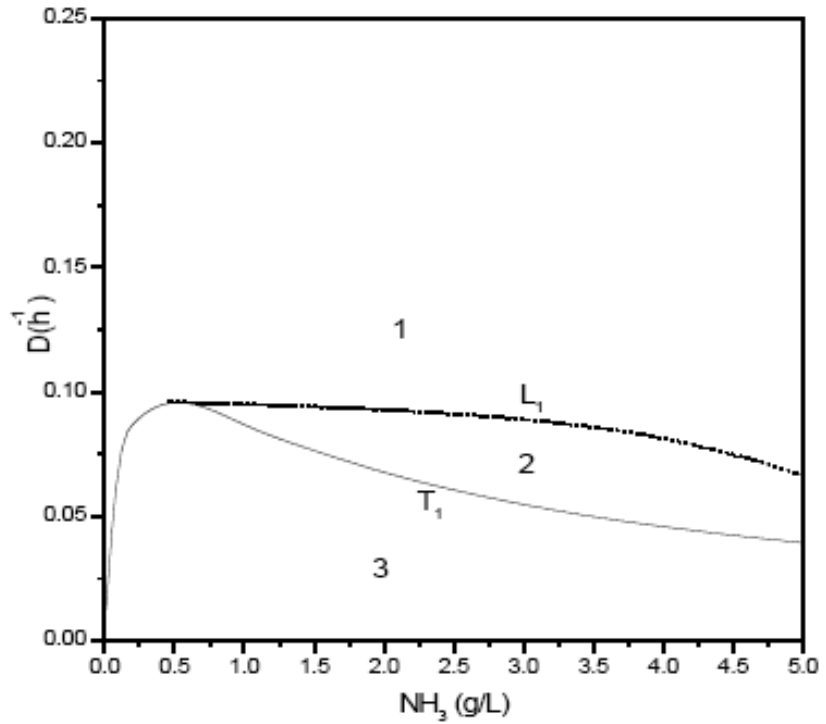

Fig. (4). Bifurcation diagram ( $\mathrm{D}$ vs $\left.\left(\mathrm{NH}_{3}\right)_{f}\right)$ for a chemostat system in which a nitrogen-fixing microbial population $\left(N_{1}\right)$ grows alone.

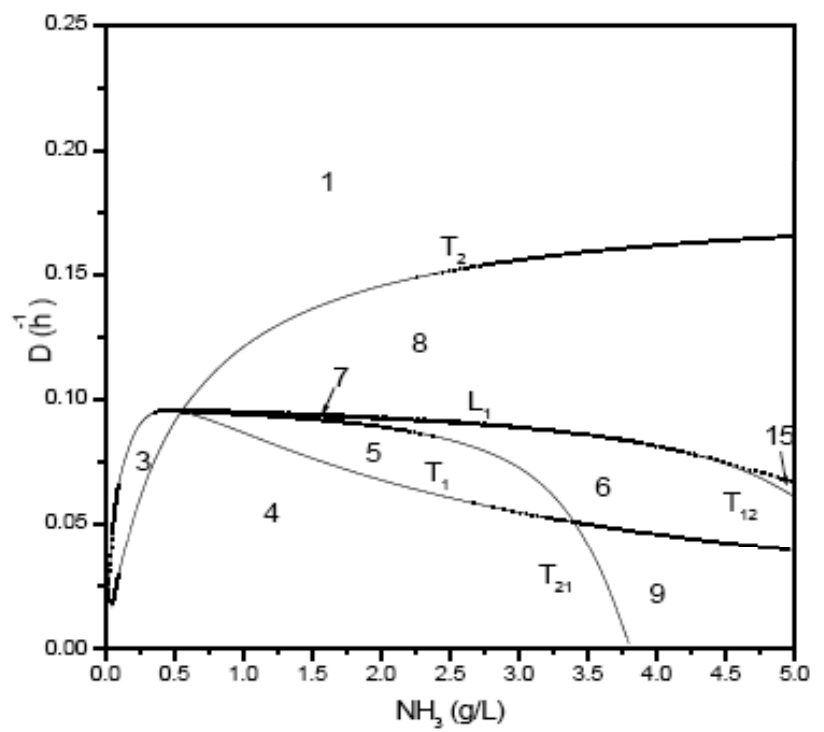

Fig. (5). Bifurcation diagram $\left(\mathrm{D}\right.$ vs. $\left.\left(\mathrm{NH}_{3}\right)_{f}\right)$ for a chemostat system in which a nitrogen-fixing microbial population $\left(N_{1}\right)$ grows together with its competitor $\left(N_{2}\right)$.

which two steady states exchange stability characteristics and one limit-point bifurcation curve $\left(\mathrm{L}_{1}\right)$ on which two steady states are born. The character of each steady state in the regions of the bifurcation diagrams is symbolized by $\mathrm{S}$ and U1. S denotes stable steady state, whereas U1 indicates an unstable steady state with one positive eigenvalue.

It is considered that, for the given set of parameter values, the population is strongly inhibited by ammonium nitrogen. In region 1 of the diagram only extinction of the populations is possible, since the washout state is the only stable ( $\mathrm{S}$ state). In region 2, multistability is obtained since two steady states are stable, the washout state and the state of survival of the $N_{l}$ population (S and $\mathrm{U} 1, \mathrm{~S}$ states, respectively). It depends on the initial state of the chemostat which of the two states will be eventually reached. In region $3 N_{1}$ population survives at S-state.
4.2. Model II: Dynamics of a Nitrogen-Fixing Population Lacking of the Competitive Advantage Towards an antagonistic for the Common Resources Population

The dynamic behaviour of the system, where population $N_{1}$ is strongly inhibited by ammonium nitrogen and at the same time has not competitive advantage towards population $N_{2}$, is presented in Fig. (5). In these conditions we expect that population $N_{1}$ can survive with difficulty.

The diagram $D$ vs $\left(\mathrm{NH}_{3}\right)_{f}$ for $\mathrm{S}_{f}=5 \mathrm{~g} / \mathrm{L}$ consists of four transcritical bifurcation curves (marked $\mathrm{T}_{1}, \mathrm{~T}_{2}, \mathrm{~T}_{12}, \mathrm{~T}_{21}$ ), on which two steady states exchange stability characteristics and one limit-point bifurcation curve $\left(\mathrm{L}_{1}\right)$ on which two steady states are born. The character of each steady state in the various regions of the diagram is symbolized by S, U1 and U2. S denotes stable steady state, whereas U1 indicates an unstable steady state with one positive eigenvalue and U2 an unstable steady state with two eigenvalues with positive real parts. In region 1 of the diagram only extinction of the populations is possible, since the washout state is the only stable. In region 2 two steady states are stable, the washout state and the state of survival of the $N_{l}$ population (multistability). It depends on the initial state of the chemostat which of the two states will be eventually reached. In regions 3-5 $N_{1}$ population survives alone in stable steady state (either $\mathrm{S}$ or U2, S states). Multistability is also observed in regions 6 , 7, 9 since both the $N_{1}$ state (U2,S/U1,S/S states, respectively) and the $N_{2}$ state (S state in all regions) are stable. In regions 8 and 15 the population $N_{2}$ dominates over $N_{1}$, as the $N_{2}$ state is the only stable. Coexistence exists only in regions 6 and 9 , but it is at unstable state (U1 state).

\subsection{Model III: Dynamics of a Nitrogen-Fixing Population Lacking of the Competitive Advantage Towards an Antagonistic for the Common Resources Population but Able to Establish Amensalistic Interactions}

In this model the population $N_{2}$ is inhibited by the compound $I$, produced during both primary and secondary metabolic growth of $N_{1}$. The population $N_{1}$ has the competitive advantage over $\mathrm{N}_{2}$ at low ammonium concentrations (e.g. $\left.\left(\mathrm{NH}_{3}\right)_{f}<0.7 \mathrm{~g} / \mathrm{L}\right)$. However, due to the high $K_{i N H 3}$ value, the population $N_{1}$ is strongly inhibited at high ammonium nitrogen concentrations, and therefore, loses its competitive advantage.

The bifurcation diagram of $D$ vs $\left(\mathrm{NH}_{3}\right)_{f}$ (for $\left.S_{f}=5 \mathrm{~g} / \mathrm{L}\right)$ is shown in Fig. (6) where the numbering of the regions is consistent with the one in the diagram shown in Fig. (5). This diagram contains four transcritical bifurcation curves $\left(\mathrm{T}_{1}, \mathrm{~T}_{2}\right.$, $\left.\mathrm{T}_{12}, \mathrm{~T}_{21}\right)$, two limit point bifurcation curves $\left(\mathrm{L}\right.$ and $\left.\mathrm{L}_{1}\right)$ and one Hopf bifurcation curve (HB) on which a stable periodic state of coexistence is born. Comparing this diagram with the one shown in Fig. (5) we observe that four new regions appear (namely 10-13) due to the additional interaction between the two populations, caused by the inhibitory compound. Furthermore, the region of multistability 15 (in which both states of survival of $N_{1}$ and coexistence are stable) is not present, whereas region 5 (in which the state of survival of $N_{1}$ is the only stable) is significantly reduced.

Multistability is observed in region 11 since the states of survival of each population alone $\left(N_{1}\right.$ and $N_{2}$ states are char- 


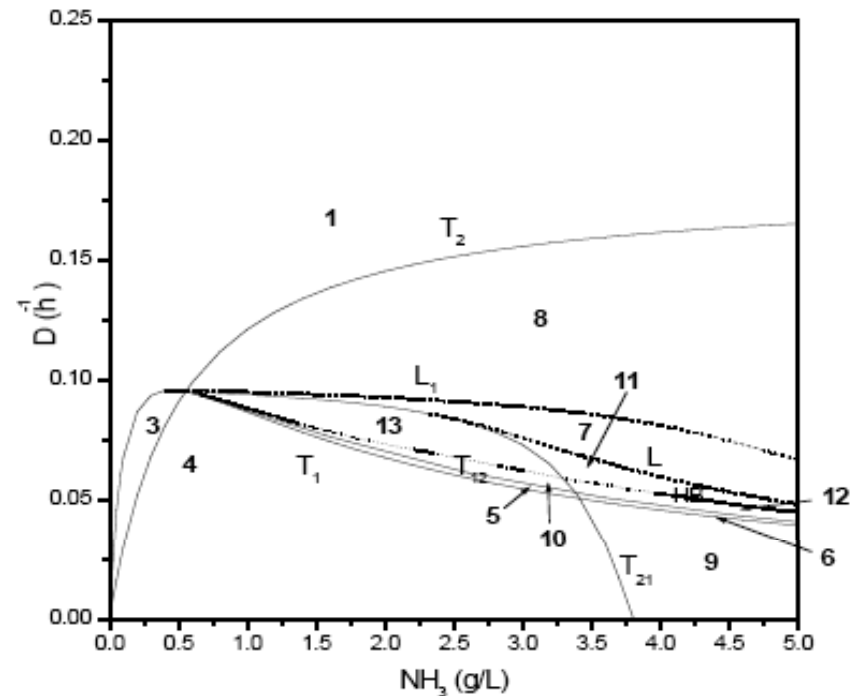

Fig. (6). Bifurcation diagram $\left(\mathrm{D}\right.$ vs $\left.\left(\mathrm{NH}_{3}\right)_{f}\right)$ for a chemostat system in which a nitrogen-fixing microbial population $\left(N_{1}\right)$, which is able to establish an amensalistic interaction in the growth environment, grows together with its competitor $\left(N_{2}\right)$.

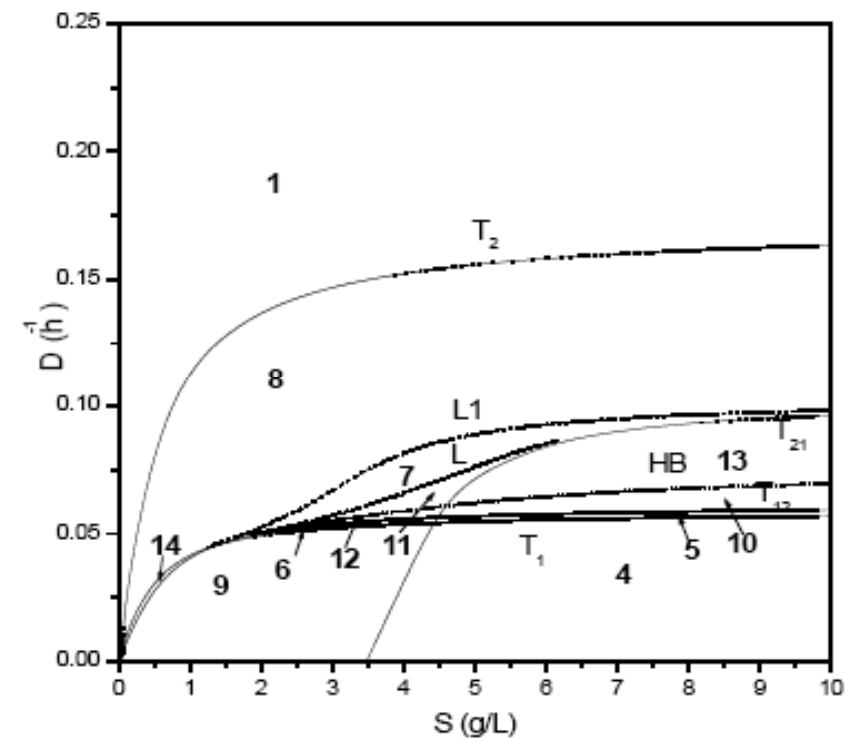

Fig. (7). Bifurcation diagram ( $D$ vs $S_{f}$ ) for a chemostat system in which a nitrogen-fixing microbial population $\left(N_{1}\right)$, which is able to establish an amensalistic interaction in the growth environment, grows together with its competitor $\left(N_{2}\right)$.

acterized as $\mathrm{U} 1, \mathrm{~S}$ and $\mathrm{S}$ states respectively), as well as the coexistence state (U1, S states), are stable. It depends on the initial conditions which state will be reached by the system. Multistability is also observed in region 13 where both the state of survival of $N_{1}$ (U1, S states) and state of survival of coexistence ( $\mathrm{S}$ state) are stable. In region 10 there is also multistability, since survival of the $N_{1}$ population is observed in a stable steady state (U1,S states) together with a stable coexistence periodic state (U2,(P) states). In region 12 survival of each population alone is observed in a stable steady state and coexistence in a stable periodic state (U1,S /S/U2,U1(P) states respectively for $N_{1} / N_{2}$ and $N_{1} N_{2}$ states). Finally, in region 14 only population $N_{2}$ can survive at stable steady state (S state).

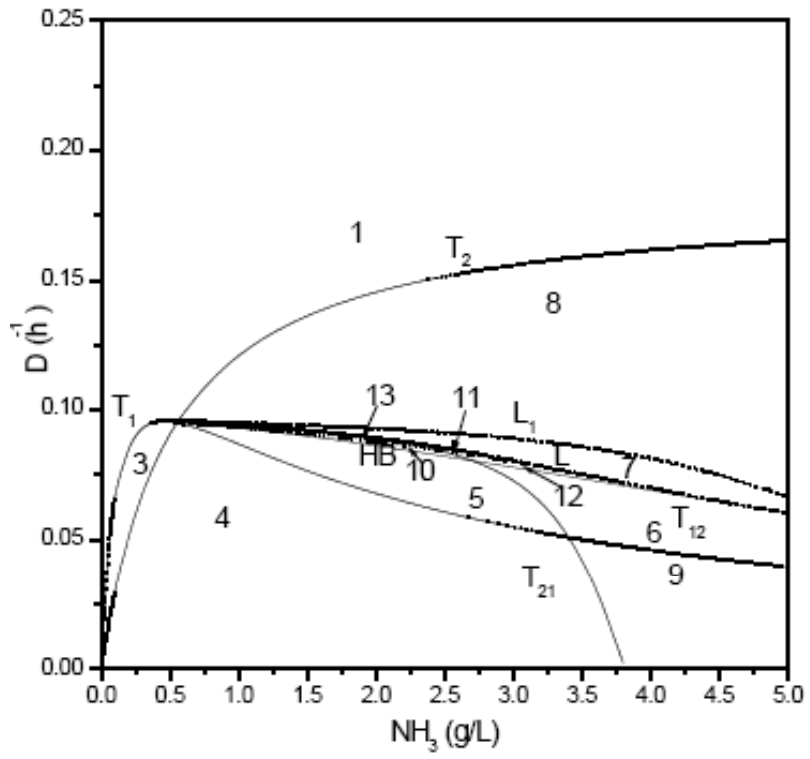

Fig. (8). Bifurcation diagram ( $\mathrm{D}$ vs $\left.\left(\mathrm{NH}_{3}\right)_{f}\right)$ for a chemostat system in which a nitrogen-fixing microbial population $\left(N_{1}\right)$, which is able to establish an amensalistic interaction in the growth environment, grows together with its competitor $\left(N_{2}\right)$.

The bifurcation diagram of $D$ vs $S_{f}$ (for $\left.\left(\mathrm{NH}_{3}\right)_{f}=3 \mathrm{~g} / \mathrm{L}\right)$ is given in Fig. (7). At this $\mathrm{NH}_{3}$ concentration, population $N_{1}$ is strongly inhibited. It is observed that population $N_{l}$ survives alone at $S>3.5 \mathrm{~g} / \mathrm{L}$ and $\mathrm{D}<0.05 \mathrm{~h}^{-1}$ (regions 4,5 ). At low carbon concentration population $N_{l}$ can survive at low dilution rate values $\left(\mathrm{D}<0.1 \mathrm{~h}^{-1}\right)$ depending on initial conditions (regions 6, 7, 9, 11 and 12). Multistability exists in regions 10 and 13 as population $N_{l}$ survives alone at stable steady state and in coexistence with $N_{2}$ at stable periodic state (region 10) or in coexistence with $N_{2}$ at stable steady state (region 13). Finally in region 8 population $N_{2}$ survives alone in stable state for a wide range of parameter values.

Fig. (8) shows that the population $N_{l}$ is strongly inhibited by ammonium nitrogen (due to the high $K_{i N H 3}$ value) and thus loses its competitive advantage even at low $\mathrm{NH}_{3}$ concentration. However, $N_{l}$ could survive by creating an unsuitable environment for its competitor. Comparing to Fig. (6) it is observed a reduction of regions $11\left(N_{l}\right.$ and $N_{2}$ and $N_{l} N_{2}$ at stable steady state) and $13\left(N_{1}\right.$ and $N_{l} N_{2}$ at stable steady state) and a benefit of region 5 where $N_{l}$ dominates. Also regions $7\left(N_{l}\right.$ and $N_{2}$ at stable steady state) and $12\left(N_{l}\right.$ and $N_{2}$ at stable steady state and $N_{l} N_{2}$ at stable periodic state) are reduced, while region $6\left(N_{l}\right.$ and $N_{2}$ at stable steady state $)$ is increased.

\section{DISCUSSION}

The role of the free-living nitrogen-fixing populations is of great significance for the biogeochemical cycle of nitrogen [1], and these bacteria have been successfully used in environmental applications [24, 28, 47] and sustainable agriculture $[10,48]$. Their ability to survive and fix nitrogen is highly influenced by ammonium nitrogen concentration in the soil. Specifically, under high ammonia concentration the nitrogenase complex becomes inactivate and the bacteria stop fixing nitrogen, while under low dissolved oxygen concentration ammonium inhibits microbial growth. Further- 
more, nitrogen fixation is a highly energy consuming process, while the carbon and energy sources are frequently present at low concentration that are actually limiting for the free-living nitrogen-fixing populations growing competitively in the soil microbial community.

The theoretical population picked in this study was sensitive to high ammonia concentrations and by default it was considered to grow with low growth rate. It was shown that the parameter set used (i.e. the low growth rate of $N_{1}$ population and the high inhibition by ammonia) constrains its ability to survive. For instance at high dilution rate values only $N_{2}$ population survives at stable steady state.

Although a number of models have been proposed for the study of the biogeochemical cycle of nitrogen [49-55], studies of the dynamics of nitrogen-fixing populations have not been published. Only some interactions between Azospirillum and other microorganisms have been previously studied using specific experimental systems [4, 56, 57]. Experimental studies regarding prey-predator interactions showed that nitrogen fixing bacteria (as well as other Gram negative species) are prey for several important soil predators such as Bdellovibrio and related organisms and protozoa [14-18].

Competitive interactions are often established between microbial populations, since many nutrients are found in limited concentrations in common habitats [4]. However, under certain conditions the presence of antagonistic populations could relieve the growth environment from certain inhibitors, such as ammonium nitrogen. Specifically the nitrogen-fixing populations can be affected by their competitors in two opposite ways $[6,7,40]$ : negatively due to the competition occurring for the common resources, and positively due to the decrease of the ammonium nitrogen concentration related to the growth of the competitive population.

In this work we show that at high concentrations of the carbon source (i.e., $S_{f}=5 \mathrm{~g} / \mathrm{L}$ ), the $N_{1}$ population can survive at stable steady state for a wide range of parameter values and operating conditions even without competitive advantage towards the second population. This fact induces major changes in regions configuration. Comparing to Kavadia et al. [41] it is observed that the growth rate of the population has a significant impact on its survival. Specifically, it is shown that $N_{1}$ population cannot survive above a threshold of the dilution rate $\left(D>0.1 \mathrm{~h}^{-1}\right)$. Also, the threshold of ammonia at which $N_{1}$ population is able to survive in multistability conditions ( $N_{1}$ and $N_{2}$ state) is getting lower. Therefore the lower growth rate of $N_{1}$ population joint with the high inhibition by ammonia concentration constrains its survival ability. At high dilution rate values $N_{2}$ is the only survivor at stable steady state regardless of ammonia and carbon concentrations.

The balance of positive - negative effects of population $N_{2}$ on the survival of $N_{1}$ could be modified by population $N_{1}$ itself, i.e., by establishing an amensalistic interaction through the production of an inhibitory substance that has a negative effect on the specific growth rate of population $N_{2}$ or by altering the operating conditions i.e. by shifting the $\mathrm{C} / \mathrm{N}$ ratio in the feed. In the present work the result of amensalism is the occurrence of coexistence state against the ability of $N_{I}$ population to survive alone at stable steady state. The threshold of dilution rate, above which only $N_{2}$ population survives, exists also in this case. When the inhibition on $\mathrm{N}_{2}$ population is strong then multistability state is favored towards coexistence state. The $N_{l}$ population can survive at stable steady state, depending on the initial conditions. Comparing to Kavadia et al. [41], the major difference observed is the narrow range of the regions in which $N_{l}$ population can survive either alone or in coexistence with $N_{2}$. Amensalism gives the ability to $\mathrm{N}_{1}$ to survive under high $\mathrm{NH}_{3}$ concentration, but the low growth rate, in regard to previous work, constrains the population at low dilution rate values. In the case of $D v s S, N_{l}$ population is at stable steady state at very low dilution rate values, while it can survive in coexistence with $N_{2}$ at low $D$ values and high $S$ concentrations.

In the case of amensalism $N_{1}$ population is able to survive in stable steady state at low carbon substrate concentration. Specifically, multistability is observed $\left(N_{1}\right.$ state and $N_{2}$ state), while at very low carbon concentration values only $N_{2}$ population survives at stable steady state. At high concentration of the carbon source, $N_{1}$ population will survive either alone or in coexistence with its competitor in stable steady state (multistability). Also at conditions of strong inhibition on $N_{2}$ population the coexistence state is diminished for the benefit of $N_{l}$ survival at steady state.

The nitrogen fixation rate is also affected by the lower growth rate of $N_{l}$ population. Although $N_{1}$ can survive in a stable steady state at high $\mathrm{NH}_{3}$ concentration, with the help of $N_{2}$, it fixes nitrogen only at low $\mathrm{NH}_{3}$ concentrations while the nitrogen fixation rate is conversely proportional to $\mathrm{NH}_{3}$ concentration and to dilution rate values. A possible effect of the lower growth rate of $N_{l}$ population on nitrogen fixation rate would be presented similar to the results of Kavadia et al. [42], but at lower dilution rate values.

\section{CONCLUSIONS}

A nitrogen-fixing population growing alone in a chemostat can survive at stable steady state only at low ammonia concentrations and dilution rate values. The presence of a second population, which has the competitive advantage over $N_{l}$ population, induces major changes in the system. The combination of ammonia inhibition and competition lead to the constraint of $N_{l}$ population at low dilution rate values. When the nitrogen-fixing population is able to establish an amensalistic interaction in the chemostat, the regions where the $N_{l}$ population survives alone at stable steady state are reduced and the coexistence region is favoured. When the inhibition on the competitive population is strong then the coexistence state is disadvantaged and multistability state is favoured.

\section{DISCLOSURE}

Models II and III are used with the permission of Elsevier (License Number 2758620561710).

\section{REFERENCES}

[1] J.R. Postgate, "The Fundamentals of Nitrogen Fixation", Cambridge University Press, London, 1982. 
[2] J.E. Bailey, and D.F. Ollis, "Biochemical Engineering Fundamentals", $2^{\text {nd }}$ ed. McGraw- Hill Int., Singapore, 1986.

[3] R.M. Atlas, and R. Bartha, "Microbial Ecology: Fundamentals and Applications", $3^{\text {rd }}$ ed. Addison-Wesley, Reading, MA, 1993.

[4] I. Cacciari, M. Del Gallo, S. Ippoliti, D. Lippi, T. Pietrosanti, and W. Pietrosanti, "Growth and survival of azospirillum brasilense and arthrobacter giacomelloi in binary continuous culture", Plant Soil, vol. 90, pp. 107-116, 1986.

[5] R.V. Solé, J. Bascompte, and J. Valls, "Stability and complexity of spatially extended two-species competition", J. Theor. Biol., vol. 159, pp. 469-480, 1992.

[6] A. Roberts, and L. Stone, "Advantageous indirect interactions in systems of competition", J. Theor. Biol., vol. 228, pp. 367-375, 2004.

[7] U. Bastolla, M. Lassig, S.C. Manrubia, and A. Valleriani, "Biodiversity in model ecosystems, I: coexistence conditions for competing species", J. Theor. Biol., vol. 235, pp. 521-530, 2005.

[8] Y. Bashan, and G. Holguin, "Azospirillum plant relationships : environmental and physiological advances (1990-1996)", Can. J. Microbiol., vol. 43, pp. 103-121, 1997.

[9] D.A. Zuberer, "Biological Dinitrogen Fixation: Introduction and Nonsymbiotic" In Principles and Applications of Soil Microbiology ed. Sylvia, D.M., Fuhrmann, J.J., Hartel, P.J. and Zuberer, D.A, New Jersey: Prentice Hall, 1998, pp. 295-321

[10] Y. Bashan, G. Holguin, and L.E. de-Bashan, "Azospirillum-plant relationships : physiological, molecular, agricultural, and environmental advances (1997-2003)", Can. J. Microbiol., vol. 50, pp. 521-577, 2004.

[11] M.G. Hassouna, M.A.M. El-Saedy, and H.M.A. Saleh, "Biocontrol of soil-borne plant pathogens attacking cucumber (Cucumis sativus) by rhizobacteria in a semiarid environment", Arid Soil Res. Rehabil., vol. 12, pp. 345-357, 1998.

[12] K. Kavitha, K.S. Meenakumari, and P. Sivaprasad, "Effect of dual inoculation of native arbuscular mycorrhizal fungi and Azospirillum on suppression of damping off in chilli", Ind. Phytopathol., vol. 56, pp. 112-113, 2003.

[13] A.M. Romero, O.S. Correa, S. Moccia, and J.G. Rivas, "Effect of Azospirillum - mediated plant growth promotion on the development of bacterial diseases on fresh-market and cherry tomato", $J$. Appl. Microbiol., vol. 95, pp. 832-838, 2003.

[14] L.M. Mallory, C.-S. Yuk, L.-N. Liang, and M. Alexander, "Alternative prey: a mechanism for elimination of bacterial species by protozoa", Appl. Environ. Microbiol., vol. 46, pp. 1073-1079, 1983.

[15] J.J. Germida, "Isolation of Bdellovibrio spp. that prey on Azospirillum brasilense in soil", Can. J. Microbiol., vol. 33(5), pp. 459-461, 1987.

[16] R. Rønn, J. Grunert, and F. Ekelund, "Protozoan response to addition of the bacteria Mycobacterium chlorophenolicum and Pseudomonas chlororaphis to soil microcosms", Biol. Fertil. Soils., vol. 33, pp. 126-131, 2001.

[17] Y. Davidov, D. Huchon, S.F. Koval, and E. Jurkevitch, "A new aproteobacterial clade of Bdellovibrio-like predators : implications for the mitochondrial endosymbiotic theory", Environ. Microbiol., vol. 8, no. 12, pp. 2179-2188, 2006.

[18] A.M. Rogosky, P.L. Moak, and E.A.B. Emmert, "Differential Predation by Bdellovibrio bacteriovorus 109J", Curr. Microbiol., vol. 52(2), pp. 81-85, 2006.

[19] N.S. Strigul, and L.V. Kravchenko, "Mathematical modeling of PGPR inoculation in the rizosphere", Environ. Modell. Softw., vol. 21, pp. 1158-1171, 2006.

[20] R.V. Klucas, "Associative Nitrogen Fixation in Plants", In Biology and biochemistry of nitrogen fixation, M.J. Dilworth, A.R. Glenn, Eds. Elsevier: Amsterdam, 1991.

[21] O. Steenhoudt, and J. Vanderleyden, "Azospirillum, a free-living nitrogen-fixing bacterium closely associated with grasses: genetic, biochemical and ecological aspects", FEMS Microbiol. Rev., vol. 24, pp. 487-506, 2000.

[22] Y. Okon, S.L. Albrecht, and R.H. Burris, "Factors affecting growth and nitrogen fixation of Spirillum lipoferum", J. Bacteriol., vol. 127, pp. 1248-1254, 1976

[23] T. Hurek, B. Reinhold, and E.G. Niemann, "Effect of oxygen on NH4+-grown continuous cultures of Azospirillum spp. and diazotrophic rods closely associated with Kallar grass". Can. J. Microbiol., vol. 33, pp. 919-922, 1987.
[24] V. Tsagou, I. Kefalogianni, K. Sini, and G. Aggelis, "Metabolic activities in Azospirillum lipoferum grown in the presence of $\mathrm{NH} 4$ +", Appl. Microbiol. Biotechnol., vol. 62, pp. 574-578, 2003.

[25] V. Tsagou, and G. Aggelis, "Growth dynamics of Azospirillum lipoferum at steady and transitory states in the presence of $\mathrm{NH} 4+$ ", J. Appl. Microbiol., vol. 100, pp. 286-295, 2006.

[26] C. Fritzsche, J. Ueckert, and E.-J. Niemann, "Growth parameters of microaerobic diazotrophic rhizobacteria determined in continuous culture". In Nitrogen Fixation M. Polsinelli, R. Materassi, and M. Vincenzini, Eds. Dordrecht, Boston, London: Kluwer Academic Publishers, 1990, pp. 232-234.

[27] C. Fritzsche, and E.G. Niemman, "Nitrogen fixation in continuous culture with NH4Cl-containing media", Appl. Environ. Microbiol., vol. 56, pp. 1160-1161, 1990.

[28] I. Kefalogianni, and G. Aggelis, "Modelling growth and biochemical activities of Azospirillum spp.", Appl. Microbiol. Biotechnol., vol. 58, pp. 352-357, 2002.

[29] H.L. Smith, and P. Waltman, "The Theory of the Chemostat: Dynamics of Microbial Competition", Cambridge studies in mathematical biology, Cambridge University Press, Cambridge, 1995, Vol. 13.

[30] M.A. Leibold, "A graphical model of keystone predation: effects of productivity on abundance, incidence and ecological diversity in communities", Am. Nat., vol. 147, pp. 784-812, 1996.

[31] V. Krivan, and A. Sikder, "Optimal foraging and predator-prey dynamics II", Theor. Popul. Biol., vol. 55, pp. 111-126, 1999.

[32] B.W. Kooi, and S.A.L.M. Kooijman, "Invading species can stabilize simple trophic systems", Ecol. Model., vol. 133, pp. 57-72, 2000.

[33] J.D. Pelletier, "Are large complex ecosystems more unstable? A theoretical reassessment with predator switching", Math. Biosci., vol. 163, pp. 91-96, 2000.

[34] S.A Richards, R.G. Nisbet, W.G. Wilson, and H.P. Possingham, "Grazers and diggers: exploitation competition and coexistence among foragers with different feeding strategies on a single resource", Am. Nat., vol. 155, pp. 266-279, 2000.

[35] V. Krivan, and J. Eisner, "Optimal foraging and predator-prey dynamics III", Theor. Popul. Biol., vol. 63, pp. 269-279, 2003.

[36] V. Krivan, "Competitive co-existence caused by adaptive predators", Evol. Ecol. Res., Vol. 5, pp. 1163-1182, 2003.

[37] G. Aggelis, D.V. Vayenas, V. Tsagou, and S. Pavlou, "Preypredator dynamics with predator switching regulated by a catabolic repression control mode", Ecol. Mod., vol. 183, pp. 453-464, 2005.

[38] D.V. Vayenas, G. Aggelis, V. Tsagou, and S. Pavlou, "Dynamics of a two-prey-one-predator system with predator switching regulated by a catabolic repression control-like mode", Ecol. Mod., vol. 186, pp. 345-357, 2005.

[39] Y. Pei, L. Chen, Q. Zhang, and C. Li, "Extinction and permanence of one-prey multi-predators of Holling type II function response system with impulsive biological control", J. Theor. Biol., vol. 235, pp. 495-503, 2005.

[40] Z. Zhang, "Mutualism or cooperation among competitors promotes coexistence and competitive ability", Ecol. Mod., vol. 164, pp. 271$282,2003$.

[41] A. Kavadia, D.V. Vayenas, S. Pavlou, and G. Aggelis, "Dynamics of free-living nitrogen-fixing bacterial populations in antagonistic conditions", Ecol. Model., vol. 200, pp. 243-253, 2007.

[42] Kavadia, D.V. Vayenas, S. Pavlou, and G. Aggelis, "Dynamics of free-living nitrogen-fixing bacterial populations and nitrogen fixation in a two-prey-one-predator system", Ecol. Model., vol. 218, pp. 323-338, 2008.

[43] A.G. Fredrickson, "Formulation of structured growth models. (Communication to the editor)", Biotechnol. Bioeng., vol. 18, pp. 720-725, 1976.

[44] J. Monod, "Research on the growth of bacterial cultures", Act. Sci. Ind., vol. 911, pp. 1-215, 1942 (in French).

[45] S.P. Graef, and J.F. Andrews, "Mathematical modelling and control of anaerobic digestion", CEP Symposium Series, vol. 70, pp. 101127, 1974.

[46] E.J. Doedel, A.R. Champneys, T.F. Fairgrieve, Y.A. Kuznetsov, B. Sandstede, and X. Wang, "AUTO 97: Continuation and Bifurcation Software for Ordinary Differential Equations, User's manual", Centre for Research on Parallel Computing, California Institute of Technology, Pasadena, 1997. 
[47] J. Ueckert, and I. Fendrik, "Continuous Culture Applications in Physiological Investigations on Diazotrophic Bacteria", In I. Fendrik, M. Del Gallo, J. Vanderleyden, M. De Zamaroczy, Eds. Azospirillum VI and related microorganisms, vol. G37, SpringerVerlag, Heidelberg, 1995.

[48] E. Bahat-Samet, S. Castro-Sowinski, and Y. Okon, "Arabinose content of extracellular polysaccharide plays a role in cell aggregation of Azospirillum brasilense", FEMS Microbiol. Lett., vol. 237, pp. 195-203, 2004.

[49] D. van Dam, and N. van Breemen, "NICCE: a model for cycling of nitrogen and carbon isotopes in coniferous forest ecosystems", Ecol. Model., vol. 79, pp. 255-275, 1995.

[50] R.R. Christian, E. Forés, F. Comin, P. Viaroli, M. Naldi, and I. Ferrari, "Nitrogen cycling networks of coastal ecosystems: influence of trophic status and primary producer form". Ecol. Model., vol. 87, pp. 111-129, 1996.

[51] A. Chapelle, A. Ménesguen, J.-M. Deslous-Paoli, P. Souchu, N. Mazouni, A. Vaquer, and B. Millet, "Modelling nitrogen, primary production and oxygen in Mediterranean lagoon. Impact of oysters farming and inputs from the watershed", Ecol. Model., Vol. 127, pp. 161-181, 2000.

[52] J.R. Kercher, and J.Q. Chambers, "Parameter estimation for a global model of terrestrial biogeochemical cycling by an iterative method", Ecol. Model., vol. 139, pp. 137-175, 2001.
[53] M. Corbeels, R.E. McMutrie, D.A. Pepper, and A.M. O'Connell, "A process-based model of nitrogen cycling in forest plantations. Part II. Simulating growth and nitrogen mineralization of Eucalyptus globulus plantations in south-western Australia", Ecol. Model., vol. 187, pp. 449-474, 2005.

[54] L.C. Bruce, D. Hamilton, J. Imberger, G. Gal, M. Gophen, T. Zohary, and K.D. Hambright, "A numerical simulation of the role of zooplankton in C, N and P cycling in Lake Kinneret, Israel", Ecol. Model., vol. 193, pp. 412-436, 2006.

[55] B.E. McNeil, R.E. Martell, and J.M. Read, "GIS and biogeochemical models for examining the legacy of forest disturbance in the Adirondack Park, NY, USA", Ecol. Model., vol. 195, pp. 281-295, 2006.

[56] M. Kloss, K.H. Iwannek, I. Fendrik, and E.G. Niemman, "Enrichment of diazotrophic bacteria from rice soil in continuous culture", Plant Soil, vol. 90, pp. 151-164, 1986.

[57] M. Mar Vázquez, S. César, R. Azcón, and J.M. Barea, "Interactions between arbuscular mychorrizal fungi and other microbial inoculants (Azospirillum, Pseudomonas, Trichoderma) and their effects on microbial population and enzyme activities in the rhizosphere of maize plants", Appl. Soil Ecol., vol. 15, pp. 261-272, 2000.

\begin{tabular}{l}
\hline Received: June 01, 2011 Revised: September 30,2011 \\
(1) Kavadia et al.; Licensee Bentham Open. \\
This is an open access article licensed under the terms of the Creative Commons Attribution Non-Commercial License \\
(http://creativecommons.org/licenses/by-nc/3.0/g) which permits unrestricted, non-commercial use, distribution and reproduction in any medium, provided the
\end{tabular}
work is properly cited. 